\title{
PENYELENGGARAN RUMAH SAKIT BERDASARKAN PRINSIP SYARIAH: STUDI PADA RUMAH SAKIT ISLAM BANJARMASIN
}

\author{
Mahmud Yusuf \\ Dosen Fakultas Ekonomi dan Bisnis Islam Universitas Islam Negeri Antasari Banjarmasin
}

\begin{abstract}
The National Sharia Council-Indonesian Ulema Council issued a fatwa No:107/ DSN-MUI/X/2016 concerning Guidelines for Managing Hospital Based on Sharia Principles as a reference for sharia hospital. Before the issuance of the fatwa, many hospitals had implemented sharia values, especially in the aspect of services, one of them was the Banjarmasin Islamic Hospital. Therefore, this study intends to ascertain in what extent of the implementation of Islamic services at the Banjarmasin Islamic Hospital and whether the aspect of the service is in accordance with the fatwa. The methodology used qualitative methods with a descriptive analysis approach, the primary data source was obtained through interview, while secondary data was obtained from library, print media, and electronics. In this study, researcher found that in general Banjarmasin Islamic Hospital had fulfilled the provisions of service in accordance with the fatwa of the National Sharia Council, but there were no presence of Sharia Supervisory Board as required by fatwa.
\end{abstract}

Abstrak: Dewan Syariah Nasional-Majelis Ulama Indonesia mengeluarkan fatwa No:107/DSNMUI/X/2016 tentang Pedoman Penyelenggaraan Rumah Sakit Berdasarkan Prinsip Syariah sebagai acuan untuk Rumah Sakit syariah. Sebelum dikeluarkanya fatwa tersebut, sudah banyak Rumah Sakit yang menerapkan nilai-nilai syariah, utamanya dalam aspek pelayanan, salah satunya adalah Rumah Sakit Islam Banjarmasin. Oleh karena itu, penelitian ini bermaksud untuk mengetahui sejauh manakah penyelenggaraan pelayanan islami pada Rumah Sakit Islam Banjarmasin dan apakah aspek pelayanan tersebut sudah sesuai dengan fatwa DSN-MUI tersebut. Metodelogi penelitian ini menggunakan metode kualitatif dengan pendekatan deskriptif analisis, sumber data primer di dapatkan melalui wawancara, sedangkan data sekunder didapatkan dari literatur perpustakaan, media cetak, dan elektronik. Dalam penelitian ini, peneliti menemukan bahwa secara umum Rumah Sakit Islam Banjarmasin telah memenuhi ketentuan pelayanan sesuai fatwa Dewan Syariah Nasional, akan tetapi belum ada lembaga Dewan Pengawas Syariah sebagaimana diwajibkan oleh fatwa.

Kata Kunci : Rumah Sakit, Pelayanan Islami, Prinsip Syariah, fatwa

\section{Pendahuluan}

Sebagai Negara dengan mayoritas umat islam di dunia, keperluan akan adanya produk syariah bukan lagi bersifat sukarela (voluntary) melainkan keharusan (mandatory). ${ }^{1}$ Islam sebagai agama memiliki konsep atau prinsip-prinsip dalam mengatur kehidupan manusia secara komprehensif dan universal, baik dalam hubungan dengan sang pencipta (babluminallah) maupun dalam hubungan sesama manusia (bablumminannas). ${ }^{2}$ Termasuk dalam hal bisnis, bisnis pada umumnya pasti ada untung dan rugi. Jadi dapat dipahami bahwa bisnis adalah suatu kegiatan usaha yang sifatnya mencari keuntungan termasuk rumah sakit.

Rumah Sakit Islam adalah rumah sakit yang seluruh aktifitasnya berdasarkan pada Maqasid alSharah al-Islamiyah yaitu menjaga agama, menjaga

\footnotetext{
1 "Rumah Sakit Syariah Semakin dibutuhkan"November 30 , 2018

https://republika.co.id/berita/ekonomi/syariahekonomi/18/10/16/pgoyb1370-rumah-sakit-syariahsemakin-dibutuhkan.

${ }^{2}$ Ika Yunia Fauzia, Prinsip Dasar Ekonomi Islam Presfektif Maqasid Al-Syariah (Jakarta: Kencana, 2014), 256.
}

hidup, menjaga akal, menjaga keturunan dan menjaga harta. Maqasid Shari'ab adalah koridor untuk pedoman bahwa segala sesuatu yang kita lakukan tidak boleh bertabrakan dengan prinsipprinsip syariah. Prinsip-prinsip tersebut dijadikan pedoman dalam pengelolaan fungsi-fungsi manajemen dalam rumah sakit, antara lain: pemasaran pengelolaan sumber daya insani, pengelolaan sarana prasarana dan pengelolaan keuangan. Rumah Sakit Islam menjadi solusi mengatasi persoalan kesehatan yang sangat kompleks secara holistik. ${ }^{3}$ Sebagaimana perintah Allah dalam Al-Qur'an surat Jasiyah ayat 18:

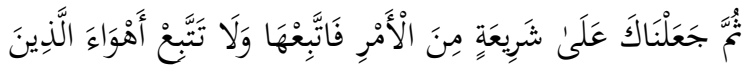

$$
\begin{aligned}
& \text { لَ الَ يَعْلَمُونَ }
\end{aligned}
$$

3 Annisa Sholiha, "Tinjauan Fatwa DSN MUI No 107/DSN-MUI/X/2016 Terhadap Penyelenggaraan Rumah Sakit Islam Sakinah Di Mojokerto" (UIN Sunan Ampel, 2018), 1-2, http://digilib.uinsby.ac.id/27589/1/Annisa\%20Sholiha _C72214066.pdf. 
Artinya: "Kemudian Kami jadikan kamu berada di atas suatu syariat (peraturan) dari urusan (agama itu), maka ikutilah syariat itu dan janganlah kamu ikuti hawa nafsu orang-orang yang tidak mengetabui"

Dewan Syari'ah Nasional Majelis Ulama Indonesia (DSN-MUI) menimbang bahwa masyarakat memerlukan penjelasan tentang pedoman penyelenggaraan rumah sakit berdasarkan prinsip syari'ah. Bahwa atas dasar pertimbangan DSN-MUI memandang perlu menetapkan Fatwa tentang pedoman penyelenggaraan rumah sakit berdasarkan prinsip syari'ah untuk dijadikan pedoman. ${ }^{4}$

Fatwa DSN No.107/DSN-MUI/X/2016 Tentang Pedoman Penyelenggaraan Rumah Sakit Berdasarkan Prinsip Syari'ah salah satunya memutuskan ketentuan akad dan ketentuan pelayanan. Ketentuan akad berbagai transaksi menurut fatwa ini harus sesuai syari'ah. Relasi antara rumah sakit dan tenaga medis, tenaga non medis dan pasien, menggunakan akad ijarah (sewa jasa). Antara rumah sakit dan pemasok alat kesehatan atau alat laboratorium, ada beberapa pilihan akad: Ijarah, Ijarah Muntabiyah Bi Al-Tamlik (sewa beli), Bai (jual beli), Mudharabah (kerjasama modal dan keahlian), dan Musyarakah (kerja sama modal). Ketentuan pelayanan menurut fatwa ini mewajibkan pihak rumah sakit untuk menerapkan kepada semua pihak yang berkepentingan. Antara lain rumah sakit dengan pasien dan rumah sakit dengan penanggung jawab pasien. ${ }^{5}$

Kenyataannya yang ada menunjukkan bahwa berada dilingkungan yang bernuansa islami tidak selalu menjadi motivasi untuk menjalankan Rumah Sakit Islam berdasarkan prinsip Syari'ah. Salah satunya adalah RS Islam Banjarmasin. Secara de jure RS Islam Banjarmasin ada pada tahun 1972. ${ }^{6}$ Penggunaan kata islam menandakan bahwa RS di kelola sesuai dengan nilai-nilai syariah, dengan tujuannya adalah menjalankan syariat Islam secara kaffah. Dan secara de facto keberadaan RS Islam Banjarmasin masih tanda tanya apakah sesuai dengan fatwa DSN MUI atau tidak sehingga memunculkan 2 (dua) rumusan masalah pada penelitian ini yaitu :

1. Bagaimana penyelenggaraan pelayanan islami pada Rumah Sakit Islam Banjarmasin?

\footnotetext{
4 Majelis Ulama Indonesia and Rakernas, Pedoman penyelenggaraan organisasi Majelis Ulama Indonesia. (Jakarta: Majelis Ulama Indonesia, 2011), 302.

5 Nanik Putpitasari, "Implementasi Fatwa DSN-MUI No.107/DSN-MUI/X/2016 Tentang Pedoman Penyelenggaraan Rumah Sakit Berdasarkan Prinsip Syari'ah” (UIN Raden Intan, 2018),
}

2. Apakah pelayanan tersebut sudah sesuai dengan fatwa Dewan Syariah Nasional-Majelis Ulama Indonesia No:107/DSN-MUI/X/2016 tentang Pedoman Penyelenggaraan Rumah Sakit Berdasarkan Prinsip Syariah?

Hal ini lah yang menjadi latar belakang peneliti mengambil tema dengan judul "Penyelenggaran Rumah Sakit Berdasarkan Prinsip Syariah (Studi pada Rumah Sakit Islam Banjarmasin)" dengan tujuan untuk mengetahui sejauh manakah penyelenggaraan pelayanan pada Rumah Sakit Islami Banjarmasin dan apakah aspek pelayanan tersebut sudah sesuai dengan fatwa DSN-MUI tersebut.

\section{Ketentuan Pelayanan Rumah Sakit Syariah}

Dewan Syariah Nasional-Majelis Ulama Indonesia telah mengeluarkan fatwa No.107/DSNMUI/X/2016 tentang Pedoman Penyelenggaraan Rumah Sakit Berdasarkan Prinsip Syariah. Ketentuan pelayanan Rumah sakitnya terdapat pada bagian kelima ketentuan terkait pelayanan. Ada 13 poin terkait pelayanan yang dijadikan acuan untuk pelayanan sesuai syariah di RS, antara lain:

1. Rumah Sakit dan semua pihak yang berkepentingan (stakeholders) wajib memenuhi hak dan kewajiban masing-masing pihak dengan sebaik-baiknya. Salah satu contoh hak yang berasal dari Rumah sakit yaitu menerima imbalan jasa pelayanan serta menentukan remunerasi, insentif, dan penghargaan. Sedangkan kewajibannya adalah memberi pelayanan kesehatan yang aman, bermutu, anti diskriminasi, dan efektifitas dengan mengutamakan kepentingan pasien sesuai dengan standar pelayanan yang Islami. Bukan hanya Rumah Sakit saja yang memiliki hak dan kewajiban, semua pihak yang didalam ruang lingkup RS pun memiliki hak dan kewajiban, untuk kenyamanan semua pihak baik itu pasien, dokter, perawat, dan karyawan yang berada diruang lingkup RS tersebut.

2. Rumah Sakit wajib memberikan pelayanan yang sesuai dengan Panduan Praktik Klinis (PPK), clinical patbway dan atau standar pelayanan yang berlaku. Menurut Menteri Kesehatan Republik Indonesia Standar Pelayanan Minimal Rumah Sakit (SPM) adalah ketentuan tentang jenis dan

http://repository.radenintan.ac.id/3257/1/SKRIPSI_p df.pdf.

6 "Rumah Sakit Islam Banjarmasin," Wikipedia bahasa Indonesia, ensiklopedia bebas, November 30, 2018, https://id.wikipedia.org/w/index.php?title=Rumah_Sa kit_Islam_Banjarmasin\&oldid=14529958. 
mutu pelayanan dasar yang merupakan urusan wajib daerah yang wajib diperoleh setiap warga negara secara minimal. Misalnya pada jenis pelayanan gawat darurat, dokter harus cepat tanggap dalam melayani pasien, tidak ada pasien yang diharuskan membayar uang muka, dan pemberian pelayanan gawat darurat yang bersertifikasi yang masih berlaku dengan tujuan keselamatan pasien yang utama. Dan beberapa jenis pelayanan yang lainnya seperti Rawat Jalan, Rawat Inap, Bedah Sentral (bedah saja), dan yang lain-lainnya.

3. Rumah Sakit wajib mengedepankan aspek kemanusiaan dalam memberikan pelayanan kesehatan yang sesuai dengan kebutuhan pasien, tanpa memandang ras, suku, dan agama. Dalam hal ini Rumah Sakit harus mengedepankan keselamatan pasien daripada memandang ras, suku, maupun agama yang dimiliki pasien. Contohnya saja ketika seseorang memerlukan bantuan hidup dasar harus dipenuhi. Upaya pertolongan segera harus diberikan semaksimal mungkin serta tidak mendahulukan administrasi Rumah Sakit hal ini lah makna dari aspek kemanusian dalam pelayanan Rumah Sakit.

4. Rumah Sakit wajib berkornitmen untuk selalu bersikap amanah, santun dan ramah, serta senantiasa berusaha untuk memberikan pelayanan yang transparan dan berkualitas. Sikap amanah, santun, dan ramah adalah tiga sikap yang membuat pelayanan pasien tersebut nyaman. Serta pelayanan yang dilakukan secara transparan adalah pelayanan yang harus memenuhi hak dan kewajiban dengan baik dan benar tanpa harus pasien tersebut diabaikan. Segala sesuatu tentang pelayanan Rumah Sakit kepada pasien harus disampaikan secara terbuka kepada masyarakat, diminta maupun tidak diminta. Hal ini akan melahirkan pelayanan yang transparan dan berkulitas.

5. Rumah sakit wajib mengedepankan aspek keadilan, dan kewajaran dalam membuat perhitungan biaya yang akan dibebankan kepada pasien. Salah satu aspek keadilan dalam perhitungan biaya kepada pasien yaitu dengan menggunakan Rekam Medis hal ini bertujuan untuk menunjang tercapainya tertib administrasi dalam rangka upaya pelayanan kesehatan dirumah sakit. Kegunaan dari rekam medis ada beberapa aspek contohnya aspek keuangan kaitannya sangat erat sekali dalam hal pembiayaan, pasien yang melakukan pembiayaan akan tercatat didalam rekam medis segala hal yang berkaitan serta biaya yang dibebenkan akan dihitung dengan seadil-adilnya tanpa membedakan mana yang miskin dan yang kaya.

6. Rumah Sakit wajib memberikan pelayanan dan konsultasi spiritual keagamaan yang sesuai kebutuhan untuk kesembuhan pasien. Proses penyembuhan penyakit tak hanya dapat dilakukan oleh tim medis, namun lebih dari itu, terapi spiritual juga diperlukan untuk proses penyembuhan seorang pasien. Bimbingan rohani untuk para pasien harus dilakukan untuk membantu para pasien sembuh secara jasmani maupun rohani.

7. Pasien dan Penanggung Jawab pasien wajib mematuhi semua peraturan dan prosedur yang berlaku di Rumah Sakit. Dalam Rumah Sakit ada beberapa peraturan dan prosedur yang tidak dapat diabaikan oleh seorang pasien, contohnya saja peraturan tidak boleh merokok pada ruang Rumah Sakit hal ini bertujuan untuk kenyamanan bersama sehingga pasien maupun penanggung jawab pasien wajib mematuhinya karna sudah menjadi tanggung jawab, serta untuk prosedur yang ditetapkan Rumah Sakit pasien dan penanggung jawab juga harus mengikuti produr tersebut.

8. Rumah Sakit, pasien dan penanggung jawab pasien wajib mewujudkan akhlak karimah. Adanya akhlak karimah merupakan sikap yang baik sesuai dengan ajaran agama Islam. Jika semua orang yang ada di rumah sakit baik itu pasien, penanggung jawab pasien memiliki akhlak karimah maka bisa dipastikan persoalanpersoalan yang sulit akan menjadi mudah, hati yang keras akan segera lembut, dan banyak orang yang akan terbantu dengan mudah. Sehingga didalam ruang lingkup rumah sakit sangat diperlukan sikap akhlak karimah yang mampu membuat kenyamanan dan ketenangan.

9. Rumah Sakit wajib menghindarkan diri dari perbuatan maksiat, risywah (suap), zhulm (penganiayaan) dan hal-hal yang bertentangan dengan syariah. Hal-hal yang bertentangan dengan syariah wajib untuk dihindari karna akan berdampak pada kerugian rumah sakit itu sendiri. Misalnya saja rumah sakit melakukan risywah maka akan berdampak dengan reputasi dan kualitas rumah sakit itu sendiri sehingga akan lebih baik hal-hal yang bertentangan dengan syariah dijauhi atau tidak dilakukan untuk kebaikan bersama.

10. Rumah Sakit wajib memiliki Dewan Pengawas Syariah. Sama seperti Lembaga Keuangan Syariah yang wajib memiliki DPS, rumah sakit syariah pun wajib memiliki DPS (Dewan Pengawas Syariah). Fungsi dari DPS ini adalah melakukan pengawasan secara periodik pada 
Lembaga Keuangan Syariah maupun Rumah Sakit Syariah yang dibawah pengawasan DSN, mengajukan usul-usul pengembangan, melaporkan perkembangan produk dan operasional, dan merumuskan permasalahanpermasalahan yang memerlukan pembahasanpembahasan DSN. Peran DPS ini sangat penting karna mengawasi jalannya Rumah Sakit Syariah sehari-hari agar selalu sesuai dengan ketentuan-ketentuan syariah yang terdapat dalam fatwa DSN MUI.

11. Rumah Sakit wajib mengikuti dan merujuk fatwa Majelis Ulama Indonesia terkait dengan masalah hukum Islam kontemporer bidang kedokteran (al-masa'il al-fiqhiyah al-waqi 'iyah althibbiyah). Istilah kedokteran kontemporer mencakup semua masalah kedokteran yang muncul pada akhir abad 20 dan awal abad 21, oleh karenanya membutuhkan penetapan hukum fikih untuk menerima, menolak, ataupun memodifikasinya agar sesuai dengan syariah islam. Bidang ini meliputi berbagai aspek yang saling berkaitan. Diantaranya ialah timbulnya penyakit-penyakit degeneratif yang mencakup gaya hidup, pekerjaan, maupun dampak lingkungan. Contohnya saja tentang masalah transplantasi organ ini bagaimana hukum islamnya, dan bagaimana islam menyikapinya maka rumah sakit wajib merujuk fatwa Majelis Ulama Indonesia tentang masalah yang ada

12. Rumah Sakit wajib memiliki panduan terkait tatacara ibadah yang wajib dilakukan pasien muslim (antara lain terkait ketentuan tata cara bersuci dan shalat bagi yang sakit). Terkait panduan pelaksanaan ibadah adalah kebutuhan spiritual. Rumah sakit wajib memfasilitasi pasien untuk memenuhi kewajiban ibadahnya sesuai dengan tingkat kemampuan pasien. Bila pasien mampu menjalankan ibadah secara mandiri rumah sakit wajib memfasilitasi ibadah pasien tetap memenuhi kaidah syar'i dengan mengingat waktu sholat, menyediakan tempat tidur yang akan jadi tempat ibadah pasien sebersih mungkin dan sesuci mungkin, memposisikan pasien menghadap kiblat, suasana ruangan yang tidak gaduh, dll. Bila pasien tidak mampu menjalankan ibadah, maka rumah sakit wajib membantunya. Bantuannya dapat berupa memberikan pemahaman ilmu bila pasien tidak mampu menjalankan ibadah karena tidak tahu cara ibadah saat kondisi sakit.
13. Rumah Sakit wajib memiliki panduan terkait standar kebersihan Rumah Sakit. Kebersihan rumah sakit adalah tempat pelayanan kesehatan yang dirancang, dioperasikan, dan dipelihara dengan sangat memperhatikan aspek kebersihan bangunan dan halaman baik fisik, sampah, limbah cair, air bersih, dan serangga/binatang penggangu. Ada beberapa persyaratan kesehatan lingkungan rumah sakit yaitu penyehatan alat-alat kesehatan di rumah sakit, penyehatan ruang bangunan dan halaman rumah sakit, dan penyehatan air.

\section{Rumah Sakit Islam Banjarmasin}

Rumah Sakit (RS) Islam Banjarmasin beralamat di Jalan Letjend. S. Parman No.88, Kota Banjarmasin, Kalimantan Selatan. RS Islam Banjarmasin merupakan amal usaha persyarikatan yang diinisiasi melalui musyawarah wilayah pimpinan Muhammadiyah Kalimantan Selatan yang ke 25. Musyawarah bertempat di Nagara, Kabupaten Hulu Sungai Selatan, berlangsung pada 15-17 April 1968 menjadi tonggak pendirian RS Islam Banjarmasin. ${ }^{7}$

Awal mulanya merupakan sebuah klinik bersalin yang bernama "Klinik Bersalin Siti Khadijah". Kemudian, pada tanggal 19 Agustus 1972 diberi nama Rumah Sakit Islam Banjarmasin dibawah yayasan Rumah Sakit Islam Banjarmasin. Dalam perkembangannya, pada tahun 2005 Yayasan Rumah Sakit Islam Banjarmasin berakhir, dan langsung dibawah Pimpinan Wilayah Muhammadiyah Kalimantan Selatan. ${ }^{8}$

RS Islam Banjarmasin telah terakreditasi tingkat "perdana" oleh Komisi Akreditasi Rumah Sakit (KARS) tertanggal 20 April 2017, melalui Standard Nasional Akreditasi Rumah Sakit (SNARS), dengan kelas tipe C. Jumlah tempat tidur sebanyak 115, dengan fasilitas kamar ruangan menggunakan kelas. Saat ini RS Islam Banjarmasin sedang mempersiapkan seluruh persyaratan yang diperlukan untuk meningkatkan status akreditasi menjadi "paripurna" pada tahun 2019.9 Dalam perkembangannya, pada tanggal 4 Januari 2018, RS Islam Banjarmasin telah bekerjasama dengan BPJS Kesehatan dengan 4 (empat) pelayanan dasar yaitu penyakit dalam, bedah umum, kandungan dan kebidanan, serta anak. ${ }^{10}$ Ditambahkan bahwa tidak ada perbedaan pelayanan untuk peserta umum maupun BPJS.

\footnotetext{
${ }^{9}$ bapak Bustani, karwayan pada RS Islam Banjarmasin, November 22, 2018.

${ }^{10}$ Ibid
}

\footnotetext{
7 "Rumah Sakit Islam Banjarmasin."

8 "Rumah Sakit Islam Banjarmasin."
} 


\section{Metodelogi Penelitian}

\section{A. Pendekatan dan Jenis Penelitian}

Metode adalah suatu cara atau jalan. Maka metode penelitian adalah cara atau jalan yang digunakan dalam penelitian. ${ }^{11}$ Metode pada penelitian ini menggunakan kualitatif. Metode kualitatif adalah penelitian tentang riset yang bersifat deskriptif dan cenderung menggunakan analisis.

Pendekatan masalah yang digunakan penyusun untuk menjawab rumusan masalah adalah menggunakan pendekatan deskriptif analisis yang artinya penelitian ini bertujuan untuk menggambarkan secermat mungkin sesuatu yang menjadi objek, gejala atau kelompok tertentu. Penelitian ini mendeskripsikan tentang pengelolaan dan pelayanan kemudian dianalisis dengan hukum Islam dan Fatwa DSN MUI NO. 107/X/2016 Tentang Pedoman Penyelenggaraan Rumah Sakit Berdasarkan Prinsip Syariah.

Jenis penelitian ini merupakan penelitian lapangan (field reseach), yaitu suatu penelitian yang dilakukan di lingkungan masyarakat tertentu, baik di lembaga-lembaga organisasi masyarakat, maupun lembaga pemerintahan, dengan tetap merujuk pada konsep-konsep yang ada. ${ }^{12}$

\section{B. Data dan Sumber Data}

Fokus penelitian ini lebih pada persoalan bentuk dan implementasi rumah sakit berdasarkan prinsip syari'ah. ${ }^{13}$ Oleh karena itu sumber data yang digunakan dalam penelitian ini adalah terbagi menjadi 2 yaitu sumber data primer dan sumber data sekunder.

Sumber data primer adalah adalah data yang diperoleh dari pihak-pihak yang terlibat. ${ }^{14}$ Data primer ini peneliti dapatkan melalui: Hasil wawancara langsung dengan narasumber dari Rumah Sakit Islam Banjarmasin. Sedangkan Sumber Data Sekunder: adalah data yang diperoleh dari pihak-pihak tidak terlibat, seperti: literatur perpustakaan, media cetak dan elektronik yang berkaitan dengan permasalahan yang dibahas.

\section{Analisis Data}

Berdasarkan data yang telah terkumpul baik data primer maupun data sekunder, peneliti melakukan analisis data dengan menggunakan

11 Hasan, Fuad dan Koentjaraningrat, Beberapa Asas Metodologi Ilmiah (Jakarta: Gremedia, 1994), 7.

12 Sumardi Suryabrata, Metodologi Penelitian, Cet. Ke-II

(Jakarta: PT Raja Grafindo Persada, 1998), 22.

13 Susiadi, Metodologi Penelitian, (Penelitian Dan Penerbitan LP2M Institut Agama Islam Negeri Lampung) (Lampung: Pusat, 2015), 20. metode analisis secara deskriptif analisis adalah penelitian yang menggambarkan data dan informasi yang berdasarkan fakta-fakta yang diperoleh di lapangan dengan melakukan kajian secara mendalam terhadap fakta-fakta yang ada dan memberikan penilaian terhadap permasalahan yang di angkat melalui interpretasi yang tepat dan akurat. ${ }^{15}$ Pola pikir induktif adalah metode yang digunakan untuk mengemukakan penyelenggaraan Rumah Sakit Islam Banjarmasin.

Metode deskriptif analisis digunakan untuk menjabarkan tentang bagaimana praktek penyelenggaraan Rumah Sakit Islam dengan pasien dalam hal pelayanan, apakah sudah sesuai atau tidak, kemudian akan dianalisis menurut fatwa DSN MUI.

\section{Pelayanan Islami pada Rumah Sakit Islam Banjarmasin $^{16}$}

Segi aspek teknis, RS Islam Banjarmasin memberikan pelayanan sesuai dengan Panduan Praktik Klinis (PPK), clinical pathway dan atau standar pelayanan kesehatan yang berlaku. RS Islam Banjarmasin memberikan komitmen untuk kesetaraan pelayanan baik terhadap muslim maupun non muslim. Nilai lebih yang didapatkan oleh pasien muslim adalah pelayanan islami. Ketersediaan pelayanan bimbingan rohani secara khusus untuk pasien muslim. Sedangkan untuk pasien nonmuslim, masih sebatas direkomendasikan untuk mendapatkan bimbingan rohani terkait.

Pelayan bimbingan rohani (bimroh) dilaksanakan setiap hari dengan cara berkeliling kesetiap ruangan. Apabila disetujui oleh pasien ataupun keluarga, pembimbing rohani akan membacakan doa untuk kesembuhan pasien. Bimbingan juga terkait dengan tata cara pelaksanaan ibadah ataupun konsultasi agama. Pembimbing berjumlah 2 (dua) orang laki-laki, melalui pergantian penjadwalan, waktu pertama pukul 08.00 s.d 14.00, dan kedua pukul 14.00 s.d 21.00. Pendampingan ketika sakaratul maut masih belum dapat dilakukan secara maksimal. Bantuan dapat diberikan untuk pemulasaran jenazah apabila diperlukan. Keperluan rohani lain untuk pasien diantaranya adalah disediakan kitab suci al-quran

\footnotetext{
${ }^{14}$ Sujadi Prawirosentono, Manajemen Produksi Dan Operasi (Jakarta: Bumi Aksara, 1997), 79.

${ }^{15}$ Kasiram, Metodologi Penelitian Kualitatif-Kuantitatif (Yogyakarta: Sukses Ofset, 2010), 175-76.

${ }^{16}$ Bapak Bustani, karwayan pada RS Islam Banjarmasin.
} 
disetiap ruangan, serta buku-buku terkait pelaksanaan ibadah. Lantunan ayat-ayat suci alquran biasanya diputarkan setiap pagi hari melalui pengeras suara. Tidak ada biaya tambahan yang dikenakan kepada pasien atas pelayanan rohani tersebut. Pelayanan rohani tersebut masih terus ditingkatkan oleh RS Islam Banjarmasin.

RS Islam Banjarmasin melakukan pembinaan kepada karyawan melalui pengajian rutin yang sifatnya wajib diikuti sebanyak 2 (dua) kali dalam 1 (satu) bulan untuk karyawan. Penceramah diundang adalah tokoh dari organisasi Muhammadiyah sendiri. Karyawan perempuan wajib menggunakan jilbab. Setiap hari-hari besar islam diadakan peringatan secara khusus.

Rumah sakit juga berupaya menghindarikan dari perbuatan maksiat dan aktifitas lain yang bertentangan dengan syariat, salah satunya melalui pembatasan jam tamu berkunjung. Dari aspek pelayanan teknis, hal yang sensitif seperti pemasangan kateter dilakukan sesuai gender.

Dalam hal aspek biaya pelayanan, penghitungan biaya yang dibebankan menurut kewajaran dan transparan. Penghitungan dilakukan melalui system informasi rumah sakit melalui sistim rincian biaya, yang dapat diakses setiap diminta oleh pasien atau pihak keluarga. Penghitungan dilakukan setiap hari, dengan pertimbangan biaya nyata yang telah dikeluarkan. Apabila dibandingkan dengan rumah sakit swasta lainnya, biaya di RS Islam Banjarmasin masih terhitung lebih rendah. Operasional keuangan RS Islam Banjarmasin sudah menggunakan jasa lembaga keuangan Syariah yaitu Bank Syariah Mandiri.

Pelayanan kebersihan RS Islam Banjarmasin, petugas melaksananakan tugasnya secara terus menerus, dan apabila ada permintaan dari pasien untuk membersihkan ruangan. Tidak ada biaya tambahan yang dibebankan. Petugas layanan kebersihan pada RS Islam Banjarmasin, diserahkan kepada koperasi karyawan yaitu koperasi Siti Khadijah.

Pengawasan managemen dan kepatuhan terhadap nilai-nilai islami, dilaksanakan oleh pemilik amal usaha, yaitu Pimpinan Wilayah Muhammadiyah. Untuk penerapan-penerapan aspek terbaik dalam hal pelayanan kesehatan, RS Islam Banjarmasin memiliki Majelis Pembinaan Kesehatan Muhammadiyah (MPKM). Meskipun begitu, RS Islam Banjarmasin belum memiliki Dewan Pengawas Syariah secara khusus.

Pengelolaan zakat, infaq dan shadaqah RS Islam bekerjasama dengan lembaga Lazismu. Apabila ada sengketa terkait pelayanan pasien dan rumah sakit, sejauh ini dapat diselesaikan melalui kekeluargaan dan musyawarah mufakat.

Dengan demikian, fatwa DSN MUI dapat menjadi tolak ukur atas legalitas praktek penyelenggaran RS Islam berdasarkan prinsip syariah. Maka jika dibandingkan antara praktek pelayanan RS Islam Banjarmasin dengan fatwa DSN MUI dapat terlihat bahwa ada beberapa kriteria-kriteria RS Islam Banjarmasin yang sesuai atau belum sesuai dengan fatwa DSN MUI, dapat dilihat pada tabel berikut:

Tabel 1

Kriteria-Kriteria Rumah Sakit Islam Banjarmasin yang sesuai/belum sesuai dengan fatwa DSN MUI

\begin{tabular}{|c|c|c|}
\hline Kriteria DSN MUI & $\begin{array}{l}\text { Sudah } \\
\text { dilaksanakan }\end{array}$ & $\begin{array}{c}\text { Belum } \\
\text { dilaksanakan }\end{array}$ \\
\hline $\begin{array}{l}\text { Rumah Sakit dan semua pihak yang berkepentingan (stakeholders) wajib } \\
\text { memenuhi hak dan kewajiban masing-masing pihak dengan sebaik- } \\
\text { baiknya. }\end{array}$ & $\sqrt{ }$ & \\
\hline $\begin{array}{l}\text { Rumah Sakit wajib memberikan pelayanan yang sesuai dengan Panduan } \\
\text { Praktik Klinis (PPK), clinical pathway dan atau standar pelayanan yang } \\
\text { berlaku. }\end{array}$ & $\sqrt{ }$ & \\
\hline $\begin{array}{l}\text { Rumah Sakit wajib mengedepankan aspek kemanusiaan dalam } \\
\text { memberikan pelayanan kesehatan yang sesuai dengan kebutuhan pasien, } \\
\text { tanpa memandang ras, suku, dan agama. }\end{array}$ & $\sqrt{ }$ & \\
\hline $\begin{array}{l}\text { Rumah Sakit wajib berkornitmen untuk selalu bersikap amanah, santun } \\
\text { dan ramah, serta senantiasa berusaha untuk memberikan pelayanan yang } \\
\text { transparan dan berkualitas }\end{array}$ & $\sqrt{ }$ & \\
\hline $\begin{array}{l}\text { Rumah sakit wajib mengedepankan aspek keadilan, dan kewajaran dalam } \\
\text { membuat perhitungan biaya yang akan dibebankan kepada pasien. }\end{array}$ & $\sqrt{ }$ & \\
\hline $\begin{array}{l}\text { Rumah Sakit wajib memberikan pelayanan dan konsultasi spiritual } \\
\text { keagamaan yang sesuai kebutuhan untuk kesembuhan pasien. }\end{array}$ & $\sqrt{ }$ & \\
\hline
\end{tabular}




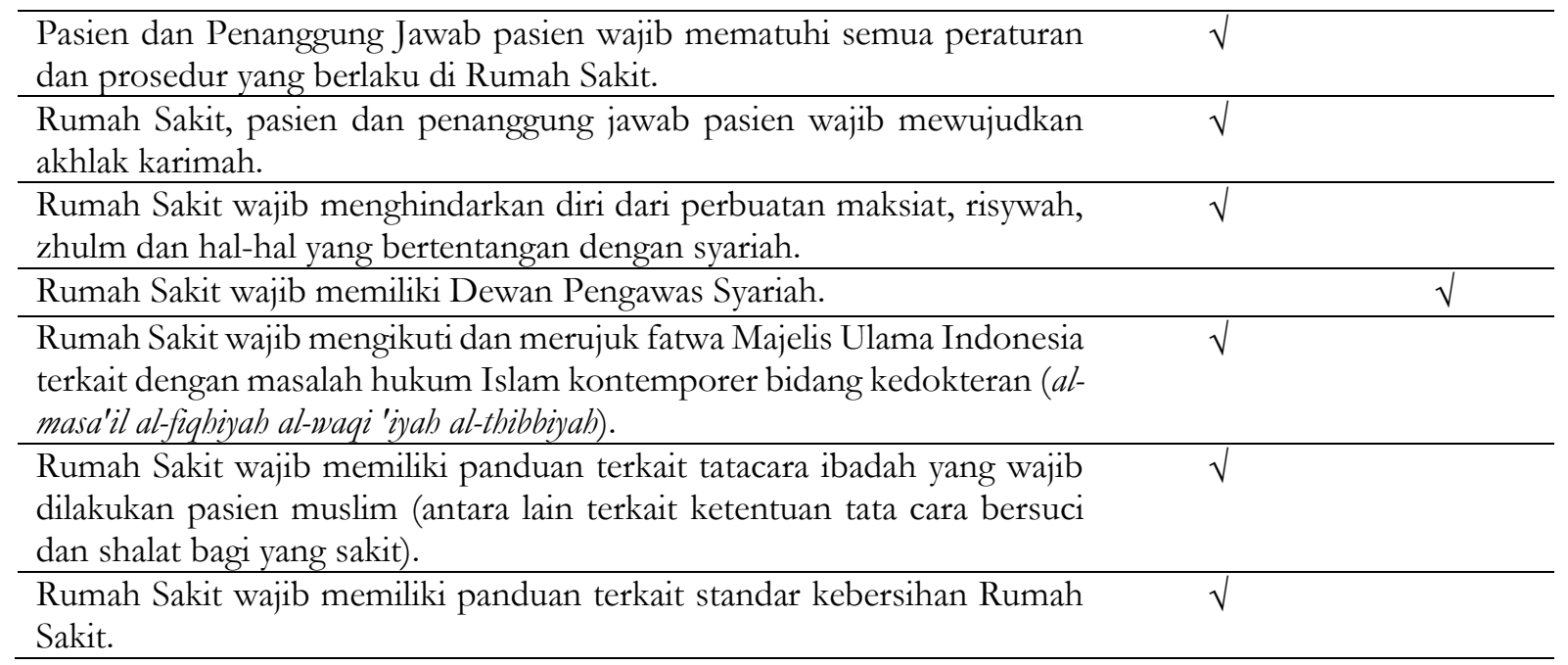

\section{Kesimpulan}

1. RS Islam Banjarmasin berupaya memaksimalkan memenuhi semua kepentingan pihak-pihak terkait, baik organisasi, pasien, maupun pemangku kepentingan yaitu Pimpinan Wilayah Muhammadiyah selaku pemilik amal usaha. RS Islam berusaha meningkatkan Akreditasi dari perdana menjadi paripurna pada 2019, yang bermakna tata kelola RS dan pelayanan akan menjadi lebih baik. Hak dan tanggung jawab masing-masing dapat terlihat jelas secara transparan. Nilai lebih yang didapatkan oleh pasien yaitu pelayanan islami, terutamanya bimbingan rohani dan keagamaan.

2. Secara umum RS Islami Banjarmasin telah memenuhi ketentuan pelayanan sesuai fatwa Dewan Syariah Nasional-Majelis Ulama Indonesia No:107/DSN-MUI/X/2016 tentang Pedoman Penyelenggaraan Rumah Sakit Berdasarkan Prinsip Syariah, akan tetapi belum ada lembaga yang diwajibkan ada pada RS Syariah menurut fatwa DSN-MUI yaitu Dewan Pengawas Syariah (DPS). Keberdaaan DPS sangat penting untuk menjamin kepatuhan terhadap nilai-nilai syariah. Dewan Pengawas Syariah secara khusus sebagaimana yang diwajibkan oleh fatwa DSN-MUI.

\section{Saran}

Berdasarkan hasil penelitian dan pembahasan yang telah disajikan maka saran yang kiranya dapat memberikan manfaat kepada pihak-pihak yang terkait atas hasil penelitian ini. Adapun saran yang dapat disampaikan adalah sebagai berikut:

1. Segera menggunakan Lembaga DPS (Dewan Pengawas Syariah) yang sesuai dengan lebel rumah sakit yang berbasis Syariah agar dapat menerapkan prinsip-prinsip Syariah.
2. Kepada pihak Rumah Sakit Islam Banjarmasin supaya lebih meningkatkan terus pelayanan Rumah sakit Islam Banjarmasin sehingga memang benar-benar menjadi Rumah Sakit yang bernuasa Islami

\section{Daftar Pustaka}

Annisa Sholiha. "Tinjauan Fatwa DSN MUI No 107/DSN-MUI/X/2016 Terhadap

Penyelenggaraan Rumah Sakit Islam Sakinah Di Mojokerto." UIN Sunan Ampel, 2018. http://digilib.uinsby.ac.id/27589/1/Anni sa\%20Sholiha_C72214066.pdf.

Bapak Bustani. karwayan pada RS Islam Banjarmasin, November 22, 2018.

Gładzik, Agnieszka, and W. Gustowski Novae Res - Wydawnictwo Innowacyjne K. Szymoński. Republika. Gdynia: Novae Res - Wydawnictwo Innowacyjne, 2015.

Hasan, Fuad dan Koentjaraningrat. Beberapa Asas Metodologi Ilmiah. Jakarta: Gremedia, 1994.

Ika Yunia Fauzia. Prinsip Dasar Ekonomi Islam Presfektif Maqasid Al-Syariah. Jakarta: Kencana, 2014.

Kasiram. Metodologi Penelitian Kualitatif-Kuantitatif. Yogyakarta: Sukses Ofset, 2010.

Majelis Ulama Indonesia, and Rakernas. Pedoman penyelenggaraan organisasi Majelis Ulama Indonesia. Jakarta: Majelis Ulama Indonesia, 2011.

Nanik Putpitasari. "Implementasi Fatwa DSNMUI No.107/DSN-MUI/X/2016 Tentang Pedoman Penyelenggaraan Rumah Sakit Berdasarkan Prinsip Syari'ah." UIN Raden Intan, 2018. http://repository.radenintan.ac.id/3257/1 /SKRIPSI_pdf.pdf. 
"Rumah Sakit Islam Banjarmasin.” Wikipedia bahasa Indonesia, ensiklopedia bebas, November 30, 2018.

https://id.wikipedia.org/w/index.php?titl e=Rumah_Sakit_Islam_Banjarmasin\&oldi $\mathrm{d}=14529958$.

Rumah Sakit Islam Semakin dibutuhkan, 20 November 2018 https://republika.co.id/berita/ekonomi/s yariah-ekonomi/18/10/16/pgoyb1370rumah-sakit-syariah-semakin-dibutuhkan

Sujadi Prawirosentono. Manajemen Produksi Dan Operasi. Jakarta: Bumi Aksara, 1997.

Sumardi Suryabrata. Metodologi Penelitian, Cet. Ke-II. Jakarta: PT Raja Grafindo Persada, 1998.

Susiadi. Metodologi Penelitian, (Penelitian Dan Penerbitan LP2M Institut Agama Islam Negeri Lampung). Lampung: Pusat, 2015. 